\title{
EFFECT OF DIFFERENT RECIPROCATING RANGES ON AMOUNT OF APICALLY EXTRUDED DEBRIS APPLYING A SINGLE-FILE RECIPROCATING INSTRUMENT
}

\author{
Motaz M. El Sadat*, Ashraf S. Refai** and Taher M. Islam ${ }^{* * *}$
}

\begin{abstract}
This study was aimed to evaluate the effect of movement kinematics and preflaring on apical debris extrusion after instrumentation with the WaveOne file. Materials and Methods: A total of 28 single-rooted teeth with curvature less than $10^{\circ}$ were selected. The teeth were assigned into 4 groups ( $=7)$; G1: $\left(150^{\circ}-30^{\circ}\right.$ with SX), G2: $\left(150^{\circ}-30^{\circ}\right) \mathrm{G} 3:\left(90^{\circ}-45^{\circ}\right.$ with SX) \& G4: $\left(90^{\circ}-45^{\circ}\right)$. WaveOne primary file (\#25 8\%) was used to prepare all the canals in 3 parts; coronal middle and apical. While the preflaring was done using Protaper SX file in G1 and G3 to half of the estimated working length. The debris collection was done using Myers and Montgomery method with Eppendorf tubes. After drying, the mean weight of debris was assessed with a microbalance. Results: Mann-Whitney U test was used to study the effect of pre-flaring and the effect of reciprocation range on debris weight $\mathrm{P}$-value $\leq 0.05$. The results showed that there was no statistically significant difference between 2 reciprocation ranges on the amount of apically extruded debris. Also, there was no statistically significant difference between the preflaring and the non-preflaring groups.
\end{abstract}

Conclusion: within the parameters of this study, the small reciprocation ranges can be used without fear. Moreover, the preflaring prior to reciprocation files is not a mandatory step.

\section{INTRODUCTION}

Thorough Chemo-mechanical preparation of the root canal system is one of the most important steps in contemporary root canal treatment. It aims to minimize the numbers of the microorganisms and pathologic debris within the root canal system. Unfortunately, one of the side effects of cleaning and shaping is the extrusion of the intracanal debris and irrigant into the periradicular tissues. The extruded material contains necrotic debris and microorganisms which may lead to interappointment flare-ups, post-operative pain and delayed wound healing ${ }^{(1,2)}$. It was postulated that the crown-down technique which utilizes coronal preflaring prior to apical preparation would decrease the amount of apically extruded debris ${ }^{(3)}$. In 2008, the concept of using single-file in reciprocating motion was introduced as a replacement for multiple-file system used in continuous rotation (4). Although using single-file in reciprocation have many advantages, they are also unable to completely prevent the extrusion of the intracanal debris and microorganisms apically ${ }^{(5)}$. The current reciprocating systems available in the market utilizes unequal form of reciprocating motion in which the counterclockwise (CCW) motion is more than the clockwise (CW). The manufacturers don't clearly state the optimum degree of reciprocation that should be used with their instruments. Few studies have been done to evaluate the effect of different reciprocating ranges and coronal flaring on the amount of apically extruded debris.

\footnotetext{
* Teaching Assistant, Endodontic Department, Faculty of Dentistry, Al-Azhar University. ** Associate Professor, Endodontic Department, Faculty of Dentistry, Al-Azhar University. *** Professor of Endodontics and Head of Endodontic Department, Faculty of Dentistry, Al- Azhar University
} 


\section{AIM OF THE STUDY}

The aim of the present study was to evaluate effect of different reciprocating ranges on amount of apically extruded debris applying a single-file reciprocating instrument.

\section{MATERIALS AND METHODS}

\section{Selection of teeth used in the study}

Twenty-eight recently extracted human single rooted teeth were collected from the Oral \& Maxillofacial Department at Al- Azhar University. The teeth were extracted for periodontal or orthodontic reasons. Only single-rooted, singlecanaled teeth, with mature apices and with curvatures less than $10^{\circ}$ (measured using the method described by Schneider ${ }^{(6)}$ were selected for this study. All teeth were radiographed from the buccal and proximal views to estimate the canal curvature and to eliminate teeth with abnormal anatomy i.e. root resorption, pulp stones etc.

Preparation of the Teeth: The root surfaces of the selected teeth were cleaned from any hard deposits using an ultrasonic scaler*. The teeth were then immersed in $5.25 \%$ sodium hypochlorite $(\mathrm{NaOCl})^{* *}$ for 10 minutes, to remove any soft tissue debris that remained on the root surfaces. Then, the prepared teeth were kept in normal saline solution $(0.9 \%)$ until the time of testing. Prior to coronal access cavity preparation, the incisal edges / buccal cusp tips of the teeth to be tested were flattened to establish an easily reproducible reference point and to standardize the length of the teeth to be $18 \mathrm{~mm}$. Furthermore, coronal access cavity was accomplished using a round diamond stone ${ }^{* * *}$ and a tapered stone with a flat end ${ }^{* * * *}$ mounted in a highspeed handpiece ${ }^{* * * * *}$. The working length for each tooth was estimated by inserting a size \#10 k-file until it appeared at the apex of the root, this length was measured and $1 \mathrm{~mm}$ was subtracted to obtain the working length of the tooth. Any root canal in which that size \#15 would not bind at the apex was excluded from the study.

Grouping and Canal Instrumentation: All the root canals in this study were prepared using the WaveOne ${ }^{* * * * * *}$ Primary file (size \#25 8\% taper) instrument in one of two reciprocation ranges: $150^{\circ}$ counterclockwise $(\mathrm{CCW})$ and $30^{\circ}$ clockwise $(\mathrm{CW})$ or $90^{\circ}$ counterclockwise $(\mathrm{CCW})$ and $45^{\circ}(\mathrm{CW})$. The teeth were also prepared with or without coronal preflaring using a Protaper $\mathrm{SX}^{* * * * * * *}$ instrument Then the teeth were divided into 4 groups ( 7 teeth each, $n=7)$ : Group (1) $\left(\mathbf{1 5 0}^{\circ} \mathbf{c c w}-\mathbf{3 0}^{\circ} \mathbf{~ c w}\right.$ (claimed manufacturer range) ${ }^{(7)}$ with preflaring using SX), Group (2) $\left(\mathbf{1 5 0}^{\circ} \mathrm{ccw}-30^{\circ} \mathrm{cw}\right.$ without preflaring Group (3) $\left(90^{\circ} \mathrm{ccw}-45^{\circ} \mathrm{cw}\right.$ with preflaring using $\mathrm{SX})$, Group (4) $\left(90^{\circ} \mathrm{ccw}-45^{\circ} \mathrm{cw}\right)$ without preflaring Prior to root canal preparation, a glide path was created using a size \#15 file to the previously estimated working length.

Preflaring with the SX instrument: In groups which underwent preflaring (Group 1 \& Group3), The Protaper SX was mounted in a 16:1 handpiece which was attached to an i-endo dual ${ }^{\bullet \bullet}$ at a speed

\footnotetext{
* Guilin woodpecker medical instrument co., Guangxi, China

** Egyptian company for house-hold bleach, Cairo, Egypt.

*** SS White Burs, Inc., New Jersy; USA

***** SS White Burs, Inc., New Jersy; USA

***** NSK, Nakanishi Inc.; Tochigi, Japan

******* Dentsply Maillefer, Ballaigues, Switzerland.

******* Dentsply Maillefer, Ballaigues, Switzerland.
}

- SP-RE16 krafit; Saeyang microtech Co., Daegu, South Korea

•• i-endo dual; Acteon, Merignac, France 
of $300 \mathrm{rpm}$ with a torque setting $1 \mathrm{Ncm}$. Initially, the access cavity was filled with $1 \mathrm{ml}$ of distilled water, then the instrument was used to enlarge the canal to half of the estimated working length using a gentle in-and-out motion as recommended by the manufacturer. Followed by $2 \mathrm{ml}$ irrigation of distilled water to flush out any coronal debris. A new Protaper SX Instrument was used to prepare each canal.

\section{Preparation using the Primary WaveOne}

files: Before preparation, distilled water $(1 \mathrm{ml})$ was placed into the canal; filling the coronal cavity. Then, a primary WaveOne file was mounted in the same handpiece and motor and set to reciprocate in one of the above-mentioned reciprocation ranges at a speed of (300 rpm). The instrument was used according to the manufacturer's instructions in a slow in-and-out pecking motion. Preparation was divided into three parts coronals, middle and apical. After preparing each part, the instrument was removed from the canal and cleaned followed by irrigation of the canal using $2 \mathrm{ml}$ of distilled water. A new WaveOne file was used to prepare each canal.

Irrigation protocol for all groups: All irrigation procedures in this study were accomplished using a gauge 30 endodontic needle $\boldsymbol{e}^{\bullet}$ using distilled water. The total amount of the irrigant was $7 \mathrm{ml}$ for all groups.

Debris Collection: The collection of the apically extruded debris was done according to the method described by Myers \& Montgomery ${ }^{(8)}$ using Eppendorf tubes figure (1) .

A total of 28 Eppendorf tubes were used for debris collection. Each Eppendorf tube was weighed using a digital microbalance $\bullet$ with a precision of 0.00001 grams. The mean of 3 consecutive readings were taken for each Eppendorf tube (Initial Weight).

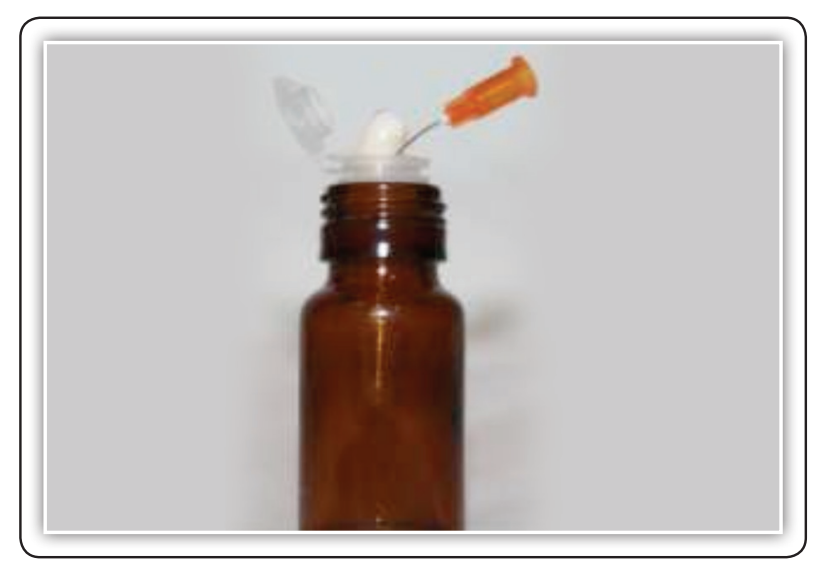

FIG (1) S howing the device used for debris collection

Furthermore, the Eppendorf tube with the attached tooth was fitted into a larger dark glass vial to prevent the operator from touching the tube directly and also to keep the root apex remained hidden during instrumentation to eliminate bias. After instrumentation, the root apex was lightly flushed with $1 \mathrm{ml}$ of distilled water to ensure any attached debris on the root surface was also collected. Following that, the Eppendorf tube was removed from the glass vial and stored in an incubator at $37^{\circ} \mathrm{C}$ for 15 days. After that the mean of 3 consecutive readings were taken for each Eppendorf tube (Final Weight). Then the Initial Weight was subtracted from the Final Weight to obtain the weight of the extruded debris. All the collected data was tabulated, calculated and statistically analyzed.

\section{RESULTS}

Numerical data were explored for normality using Kolmogorov-Smirnov and Shapiro-Wilk tests. Apically extruded debris weight data showed non-parametric distribution. Mann-Whitney U test was used to study the effect of preflaring and the effect of reciprocation range on apically extruded debris weight. The Mean (SD) of all groups are presented in Table (1)

- KerrHawe Irrigation Probe; KerrHawe SA, Bioggio, Switzerland

•• AT21 comparator; Mettler Toledo, Greifensee-Zurich, Switzerland 
TABLE (1) Descriptive statistics of debris weight (g)

\begin{tabular}{|c|c|c|c|c|c|}
\hline Group & Mean & SD & Median & Minimum & Maximum \\
\hline G1 (150-30) SX & 0.00012 & 0.00021 & 0.00005 & 0.00001 & 0.00060 \\
\hline G2 (150-30) & 0.00019 & 0.00016 & 0.00012 & 0.00003 & 0.00043 \\
\hline G3 (90-45) SX & 0.00018 & 0.00020 & 0.00008 & 0.00001 & 0.00047 \\
\hline G4 (90-45) & 0.00022 & 0.00032 & 0.00003 & 0.00001 & 0.00081 \\
\hline
\end{tabular}

\section{Effect of preflaring using SX}

Mann-Whitney $\mathrm{U}$ test was used for the evaluation of the groups in this section at $P$-value $\leq 0.05$. Presented in table (2). The statistical analysis showed that there was no significant difference between apically extruded debris weights with and without preflaring when using any of the two ranges at $P$-value $\leq 0.05$.

TABLE (2) Comparison between apically extruded debris weights with and without preflaring

\begin{tabular}{|c|c|c|c|c|c|}
\hline \multirow{2}{*}{$\begin{array}{c}\text { Reciprocation } \\
\text { range }\end{array}$} & \multicolumn{2}{|c|}{ Preflaring } & \multicolumn{2}{c|}{ No preflaring } & \multirow{2}{*}{ P-value } \\
\cline { 2 - 5 } & Mean & SD & Mean & SD & \\
\hline $150-30$ & 0.00012 & 0.00021 & 0.00019 & 0.00016 & 0.159 \\
\hline $90-45$ & 0.00018 & 0.00020 & 0.00022 & 0.00032 & 0.898 \\
\hline
\end{tabular}

*: Significant at $P \leq 0.05$

\section{Effect of reciprocation range:}

Mann-Whitney $\mathrm{U}$ test was used for the evaluation of the groups in this section at $P$-value $\leq 0.05$. (Presented in table (3). The statistical analysis showed that there was no significant difference between the apically extruded debris weights with the two ranges of reciprocation with or without preflaring at $P$-value $\leq 0.05$.

TABLE (3) Comparison between apically extruded debris weights with the two reciprocation ranges

\begin{tabular}{|c|c|c|c|c|c|}
\hline \multirow{2}{*}{ Preflaring } & \multicolumn{2}{|c|}{$150-30$} & \multicolumn{2}{c|}{$90-45$} & \multirow{2}{*}{ P-value } \\
\cline { 2 - 6 } & Mean & $S D$ & Mean & SD & 0.403 \\
\hline $\begin{array}{c}\text { Preflaring } \\
\begin{array}{c}\text { No } \\
\text { preflaring }\end{array}\end{array}$ & 0.00012 & 0.00021 & 0.00018 & 0.00020 & 0.442 \\
\cline { 2 - 6 } & 0.00019 & 0.00016 & 0.00022 & 0.00032 & 0.42 \\
\hline
\end{tabular}

*: Significant at $P \leq 0.05$ 


\section{DISCUSSION}

The apical extrusion of debris that occurs during chemo-mechanical preparation of the root canal into the periapical tissues is considered one of the main causes of interappointment flare-up and postoperative pain as well as delayed healing ${ }^{(1,2)}$. This is an inevitable side effect of all instrumentation techniques. In 2013, Yared and Ramli (9) concluded that "The concept of root canal preparation with only one file used in reciprocation is promising". The available brands in the market are WaveOne and the Reciproc instruments. In this study WaveOne was selected because of its availability. Moreover, WaveOne primary file (\#25 8\%) was selected because it is the most commonly used size.

In regard to the reciprocation ranges, both the Reciproc and the WaveOne are used in preset dedicated reciprocation motors with a specific range of motion described by the manufacturer. Kim et al, (10) in their research, claimed that the manufacture range is $170^{\circ} \mathrm{ccw}-50^{\circ} \mathrm{cw}$ while Saber and $\mathrm{Abu} \mathrm{El}$ Sadat ${ }^{(77)}$ claimed that it is $150^{\circ} \mathrm{ccw}-30^{\circ} \mathrm{cw}$. There is no clear reference from the manufacturer for these ranges. Saber and Abu El Sadat ${ }^{(77)}$ in 2013 evaluated the WaveOne file in 3 different ranges of reciprocation regarding the cyclic fatigue and the shaping ability. They found that the range $\left(90^{\circ}\right.$ $\mathrm{ccw}-45^{\circ} \mathrm{cw}$ ) showed the highest resistance to cyclic fatigue when compared to the other 2 ranges. In the present study, the used reciprocating ranges were $\left(150^{\circ} \mathrm{ccw}-30^{\circ} \mathrm{cw}\right)$ representing the manufacturer range and $\left(90^{\circ} \mathrm{ccw}-45^{\circ} \mathrm{cw}\right)$; which was the range that showed highest resistance to cyclic fatigue in Saber \& Abu El-Sadat study.

In this study, preflaring was accomplished using the SX instrument which is an established preflaring tool that has a taper greater than WaveOne files. Moreover, Single-rooted teeth with single root canals and curvature between $0^{\circ}-10^{\circ}$ were used for the sake of standardization and to avoid possible complication associated with curved multi-rooted teeth It has also been established that canal curvature has no effect on the amount of apically extruded debris ${ }^{(11)}$. In this research, irrigation was accomplished using distilled water delivered in a 30-gauge side-vented endodontic irrigating needle. Distilled water was preferred over $\mathrm{NaOCl}$ as sodium crystals may form after desiccation of the samples ${ }^{(5)}$. The experimental model used in this study to assess the amount of apically extruded debris was the one described by Myers and Montgomery ${ }^{(8)}$.

The aim of this study was to evaluate the amount of the apically extruded debris when using the WaveOne instrument in two reciprocating ranges with and without preflaring. All the reciprocating ranges evaluated in this study showed some degree of apically extruded debris.

Within the parameters of this study, when comparing between the 2 reciprocation ranges, although the Mean (SD) of the $\left(90^{\circ} \mathrm{ccw}-45^{\circ} \mathrm{cw}\right)$ was higher than $\left(150^{\circ} \mathrm{ccw}-30^{\circ} \mathrm{cw}\right)$, the results showed that there was no statistically significant difference between them in regards to the amount of apically extruded debris whether preflaring was done or not $(P \leq 0.05)$.

The reason behind this may be attributed to the fact that instruments used in $\left(150^{\circ} \mathrm{ccw}-30^{\circ}\right.$ $\mathrm{cw})$ reciprocation complete one revolution in 3 cutting cycles (ccw-cw strokes). To further clarify, this translates into $450^{\circ}$ of ccw motion and $90^{\circ}$ of $\mathrm{cw}$ motion. On the other hand, instruments used in $\left(90^{\circ} \mathrm{ccw}-45^{\circ} \mathrm{cw}\right)$ reciprocation will complete one revolution in 8 cutting cycles, this translates into a total of $720^{\circ}$ of ccw motion and $360^{\circ}$ of $\mathrm{cw}$ motion. When using $\left(90^{\circ} \mathrm{ccw}-45^{\circ} \mathrm{cw}\right)$ the amount of ccw motion is 1.6 times more when compared to $\left(150^{\circ} \mathrm{ccw}-30^{\circ} \mathrm{cw}\right)$. On the other hand, when using the $\left(90^{\circ} \mathrm{ccw}-45^{\circ} \mathrm{cw}\right)$ the amount of $\mathrm{cw}$ motion is 4 times more when compared to $\left(150^{\circ} \mathrm{ccw}-30^{\circ} \mathrm{cw}\right)$. To build on this, the WaveOne instrument has a cross section with a reverse helix that cuts on the 
ccw motion unlike conventional rotary instruments used in continuous rotation ${ }^{(7,12,13)}$. Logic would imply more debris should have been extruded using $\left(90^{\circ} \mathrm{ccw}-45^{\circ} \mathrm{cw}\right)$ due to the larger amount of $\mathrm{ccw}$ motion, on the contrary, the amount of $\mathrm{cw}$ motion, which displaces debris coronally and disengages the instrument from the canal ${ }^{(7,12,13)}$, is 4 times more when compared to $\left(150^{\circ} \mathrm{ccw}-30^{\circ} \mathrm{cw}\right)$. This may account for the lack of significance between the two reciprocation ranges with regards to the amount of apically extruded debris. This result is in agreement with previous research which showed that there was no significant difference between smaller and larger reciprocating ranges in regards to apically extruded debris ${ }^{(14,15)}$.

When comparing the effect of preflaring within each reciprocation range, the preflaring groups showed a lower Mean (SD) when compared to the non preflaring groups, although there was no significant difference between the amounts of apically extruded debris $(P \leq 0.05)$. This may be due to the fact that the WaveOne file was used to prepare the canals in 3 "waves"; coronally, middle and apically. Between each preparation wave the instrument was removed cleaned and reinserted after irrigation of the canal, this may have negated the potential effect of preflaring using the SX instrument. Because the first two waves coronal and middle in effect act as a preflaring instrument. But this is in disagreement with the research done by Topçuoğlu et al, ${ }^{(16)}$ which showed that the preflaring reduced the amount of the apically extruded debris when using reciprocating single files. The differences in the results may be attributed to the different preflaring instruments which they used (gates-glidden drills size 2, 3 and 4). On the other hand, it is not clearly stated to which depth preflaring was performed i.e. if the depth of the penetration was further into the canal than depth used in this study, this may have contributed to more dentin interference being removed during preflaring phase and hence extruding less debris in groups that underwent preflaring. Although it is clear from the results of this study that the amount of apically extruded debris wasn't affected by the different reciprocation ranges with or without preflaring, care should be taken when transferring these results directly to the clinical situation due to differences in anatomy, canal sizes, difficulties associated with tooth length determination as well as the fact in apical extrusion studies, there is no simulation of periapical tissues which act as natural barriers to apical extrusion ${ }^{(5)}$.

\section{CONCLUSIONS}

Within the parameters of this study, the following conclusions could be drawn:

1. Smaller reciprocation ranges can be used without fear of excessive extrusion of debris.

2. Preflaing before using reciprocating instruments is not a mandatory step.

\section{REFERENCES}

1. Seltzer S, Naidorf I. Flare-ups in endodontics: I. etiological factors. J Endod. 1985; 11:472-8.

2. Wittgow W Jr, Sabiston C Jr. Microorganisms from pulpal chambers of intact teeth with necrotic pulps. J Endod. 1975; 1:168-71.

3. Tanalp J, Kaptan F, Sert S, Kayahan B, Bayirl G. Quantitative evaluation of the amount of apically extruded debris using 3 different rotary instrumentation systems. Oral Surg Oral Med Oral Pathol Oral Radiol Endod. 2006; 101:250-7.

4. Yared G. Canal preparation using only one ni-ti rotary instrument: preliminary observations. Int Endod J. 2008; 41:339-44.

5. Tanalp J, Güngör T. Apical extrusion of debris: a literature review of an inherent occurrence during root canal treatment. Int Endod J. 2014; 47:211-21.

6. Schneider S. A comparison of canal preparations in straight and curved root canals. Oral Surg Oral Med Oral Pathol. 1971; 32:271-5.

7. Saber S, Abu El Sadat S. Effect of Altering the Reciprocation Range on the Fatigue Life and the Shaping Ability of waveone Nickel-Titanium Instruments. J Endod 2013; 39:685-8 
8. Myers G, Montgomery S. A comparison of weights of debris extruded apically by conventional filing and canal master techniques. J Endod. 1991; 17:275-9.

9. Yared G, Ramli G. Single file reciprocation: a literature review. ENDO (Lond Engl) 2013; 7:171-7.

10. Kim H, Kwak S, Cheung G, Ko D, Chung S, Lee W. Cyclic fatigue and torsional resistance of two new nickel-titanium instruments used in reciprocation motion: Reciproc versus waveone. J Endod 2012; 38:541-4.

11. Hinrichs R, Walker W, Schindler W. A comparison of amounts of apically extruded debris using handpiece-driven nickel-titanium instruments systems. J Endod. 1998; 24:102-6.

12. Plotino G, Grande N, Testarelli L, Gambarini G. Cyclic fatigue of reciproc and waveone reciprocating instruments. Int Endod J 2012; 45:614-8.

13. Grande N, Ahmed H, Cohen S, Bukiet F, Plotino G. Current assessment of reciprocation in endodontic prepa- ration: a comprehensive review - part i: historic perspectives and current applications. J Endod 2015; 41:1778-3.

14. Arslan H, Doğanay E, Alsancak M, Çapar I, Karataş E, Gündüz H. Comparison of apically extruded debris after root canal instrumentation using reciproc ${ }^{\circledR}$ instruments with various kinematics. Int Endod J (in press) doi:10.1111/iej.12449.

15. Karataş E, Arslan H, Kırıcı D, Alsancak M, Çapar I. Quantitative evaluation of apically extruded debris with twisted file adaptive instruments in straight root canals: reciprocation with different angles, adaptive motion and continuous rotation. Int Endod J (in press) doi:10.1111/iej.12461 .

16. Topçuoğlu H, Üstün Y, Akpek F, Aktı A, Topçuoğlu G. Effect of coronal flaring on apical extrusion of debris during root canal instrumentation using single-file systems. Int Endod J 2015 (in press); doi:10.1111/iej.12520. 
